\title{
Psychometric properties of the World Health Organization quality of life assessment - brief in methadone patients: a validation study in northern Taiwan
}

Tiffany Szu-Ting Fu', Yung-Change Tuan², Muh-Yong Yen ${ }^{3}$, Wei-Hsin Wu ${ }^{4}$, Chun-Wei Huang ${ }^{5}$, Wei-Ti Chen ${ }^{6}$, Chiang-Shan $\mathrm{RLi}^{7}$ and Tony Szu-Hsien Lee ${ }^{1 *}$

\begin{abstract}
Background: Quality of life (QOL) is an important outcome measure in the treatment of heroin addiction. The Taiwan version of the World Health Organization Quality of Life assessment (WHOQOL-BREF [TW]) has been developed and studied in various groups, but not specifically in a population of injection drug users. The aim of this study was to analyze the psychometric properties of the WHOQOL-BREF (TW) in a sample of injection drug users undergoing methadone maintenance treatment.

Methods: A total of 553 participants were interviewed and completed the instrument. Item-response distributions, internal consistency, corrected item-domain correlation, criterion-related validity, and construct validity through confirmatory factor analysis were evaluated.

Results: The frequency distribution of the 4 domains of the WHOQOL-BREF (TW) showed no floor or ceiling effects. The instrument demonstrated adequate internal consistency (Cronbach's alpha coefficients were higher than 0.7 across the 4 domains) and all items had acceptable correlation with the corresponding domain scores $(r=0.32-0.73)$. Correlations $(p<0.01$ ) of the 4 domains with the 2 benchmark items assessing overall QOL and general health were supportive of criterion-related validity. Confirmatory factor analysis yielded marginal goodness-of-fit between the 4-domain model and the sample data.

Conclusions: The hypothesized WHOQOL-BREF measurement model was appropriate for the injection drug users after some adjustments. Despite different patterns found in the confirmatory factor analysis, the findings overall suggest that the WHOQOL-BREF (TW) is a reliable and valid measure of QOL among injection drug users and can be utilized in future treatment outcome studies. The factor structure provided by the study also helps to understand the QOL characteristics of the injection drug users in Taiwan. However, more research is needed to examine its test-retest reliability and sensitivity to changes due to treatment.
\end{abstract}

Keywords: Methadone, Psychometrics, Quality of life, WHOQOL-BREF, Injection drug users, Taiwan

\footnotetext{
*Correspondence: tonylee@ntnu.edu.tw

'Department of Health Promotion and Health Education, National Taiwan Normal University, No. 162, He-ping East Road, Section 1, Taipei 10610,

Taiwan

Full list of author information is available at the end of the article
} 


\section{Background}

Injecting use of heroin has been a risk factor for acquiring infectious diseases, including the human immunodeficiency virus (HIV) and hepatitis $\mathrm{C}$ virus (HCV) [1]. In Taiwan, it is estimated that $34 \%$ of the HIV cases are injection drug users (IDUs) [2]. To stem the spread of HIV, methadone maintenance treatment (MMT) was adopted in 2006 in Taiwan. Studies evaluating the efficacy and effectiveness of MMT have been centered on the objective outcome criteria, such as retention, death, heroin use, and crime rates [3]. However, it is not clear how IDU perceive the effects of treatment and, in particular, how treatments have impacted their quality of life [4]. Drug abuse or dependence is associated with multiple negative consequences physically and mentally as well as in social relations and work [5]. Although methadone alleviates the physical symptoms of opioid dependence [6], how it impacts the quality of life of IDUs remains to be evaluated. Therefore, it is important to consider subjective patients' perception in the assessment of harm reduction programs by means of self-reported measures $[7,8]$.

Because heroin addiction is a chronic and relapsing condition, which causes substantial impairments in both the physical and psychosocial health of the patients, the quality of life (QOL) scales have been used as an outcome measure to evaluate and to quantify the changes in patients' functioning and well-being during treatment $[9,10]$. The generic QOL instruments commonly used in the MMT-related studies include the Nottingham Health Profile (e.g., [11,12]), the Quality of Well-Being Scale (e.g., [13]), the Medical Outcomes Study 36-Item Short-Form Health Survey (e.g., $[14,15]$ ), and the short version of the World Health Organization Quality of Life assessment (WHOQOL-BREF) (e.g., [16,17]). Of these generic QOL measures, only the WHOQOL is developed by first establishing the definition of subjective QOL as 'an individual's perception of their position in life in the context of the culture and value systems in which they live, and in relation to their goals, expectations, standards and concerns' [18-20].

The WHOQOL contains 100 items (WHOQOL-100) [20]. To minimize the burden of the respondents and to ameliorate time constraint, a shortened, 26-item version, the WHOQOL-BREF, was developed [21]. The WHOQOL-BREF was translated for use in Taiwan (TW) according to the WHO international guidelines [22], and shown to have good test-retest reliability, internal consistency, content and discriminant validity [23]. The psychometric properties of the WHOQOLBREF (TW) have been explored earlier (e.g., [24-26]). For example, Chen et al. [24] demonstrated adequate reliability and validity of the WHOQOL-BREF (TW) and that suggested that it may be used as a health indicator in different age groups from early adolescence to adulthood. In addition, it has been demonstrated that the instrument is suitable for the assessment of health status perceived by persons with spinal cord injury [27] and hemodialysis patients [28].

However, to our knowledge, few studies to date have provided evidence of the reliability and validity of the WHOQOL-BREF (TW) in IDUs enrolled in a MMT program. In order to use the instrument with the IDUs, the suitability of the WHOQOL-BREF (TW) needs to be validated prior to its clinical application to this population group [29]. The purpose of the present study was therefore to examine the item-response distribution, internal consistency, corrected item-domain correlation, criterionrelated validity, and construct validity of the WHOQOLBREF (TW) in IDUs under MMT.

\section{Methods}

\section{Participants and procedure}

A total of 599 eligible participants who fulfilled the Diagnostic and Statistical Manual of Mental Disorders (DSM) version IV criteria for heroin abuse from 4 methadone outpatient clinics in northern Taiwan were invited during the years 2008 and 2009 to participate in the study. Ethics approval for this study was obtained from the Institutional Review Board of Human Subjects Protection at the Taipei Medical University (P960205) and the Taipei City Hospital (TCHIRB-970404-E). 553 participants were interviewed and 46 withdrew their participation without signing the consent. All participants met the following eligibility criteria: heroin abuse/dependence, enrolled in methadone outpatient treatment, aged 18 or above and being able to read. They were enrolled in a MMT program at the time of interview. After completion, participants were reimbursed for $\$ 100 \mathrm{New}$ Taiwan dollars (approximately 3 US dollars).

\section{Outcome measure}

The self-administered WHOQOL-BREF (TW) (Additional file 1) contains 28 items, including 2 benchmark items assessing overall QOL and general health [22]. The remaining 26 items consist of 24 standard items from the original WHOQOL-BREF in 4 domains: physical health, psychological health, social relationships, and environment, plus 2 culturally relevant items: "Do you feel respected by others?" (social relationships domain), and "Are you usually able to get the things you like to eat?" (environment domain).

Scoring of the WHOQOL-BREF (TW) concerns "how good", "how satisfied", "how completely", "how often" or "how much" the participant felt in the last 2 weeks and is rated on a 5 -point Likert scale. The 2 benchmark items (overall QOL and general health) were calculated as a single score with a range of 1-5. Domain scores were calculated by multiplying the mean score for all items included 
in each domain by a factor of 4 [21]. Therefore, potential scores for each domain range from 4 to 20 , with higher scores indicating better QOL.

\section{Data analysis}

Descriptive analysis was used to report the demographic and clinical characteristics of the participants. The response distributions of domain and item scores were calculated to identify problematic items. Floor and ceiling effects were considered significant if the percentage of participants achieving the lowest and the highest scores exceeds $20 \%$ of the total sample [30]. To test reliability, the Cronbach's alpha coefficient was used to evaluate the internal consistency of each domain of the WHOQOLBREF (TW). Cronbach's alpha values equal to or greater than 0.70 were considered satisfactory [31]. The corrected item-domain correlation was also reported to examine the homogeneity of the items in each domain. The criterionrelated validity of the WHOQOL-BREF (TW) was evaluated by measuring the strength of Pearson's $r$ correlation between each item/domain scores and two criteria (i.e., overall QOL and general health). The strength of relationship of 0.40 or above was considered satisfactory $(r \geq 0.81-1.0$ as excellent, $0.61-0.80$ very good, $0.41-0.60$ good, 0.21-0.40 fair and $\leq 0.20$ poor) [31].

For construct validity, confirmatory factor analysis based on a maximum likelihood estimate, was conducted to validate whether the existing domain structure could be fit to the IDUs enrolled in a methadone treatment program while controlling for age, education, gender, HIV, HCV, duration of heroin use, methadone dose and days in MMT at study interview. The goodnessof-fit indicators include: the comparative fit index (CFI) and the non-normed fit index (NNFI) with values above 0.90 as well as the root mean square error of approximation (RMSEA) with values lower than 0.08 [32]. Model modifications were performed when the modification index suggests adding an error covariance between two items or adding a path from domain to item. Based on the two indices, the suggestion, with the greatest decrease in chi-square value, was selected to modify the model until the above criteria $(\mathrm{CFI}>0.90, \mathrm{NNFI}>0.90$, and RMSEA $<$ 0.08 ) were met [33].

\section{Results}

\section{Characteristics of the participants}

Of participants, 510 completed the WHOQOL-BREF (TW) in a private room at the clinic of about 15 minutes and used in the analysis. The data of 43 patients were excluded from further analysis because they did not respond to all WHOQOL-BREF questions. Table 1 shows the demographic and clinical characteristics of these 510 participants. The mean age of the participants was 40.7 (standard deviation $[\mathrm{SD}]=9.1$ ) and mean duration of
Table 1 Demographic and clinical characteristics of the participants $(n=510)$

\begin{tabular}{ll}
\hline Characteristics & Mean (S.D.) \\
\hline Age groups (year) & $40.7(9.1)$ \\
Duration of heroin use (years) & $11.96(7.78)$ \\
Average MMT dose (mg/day) & $51.62(32.40)$ \\
Duration in MMT (days) & $183.86(150.90)$ \\
& Number (\%) \\
Gender & \\
Male & $443(86.9)$ \\
Female & $67(13.1)$ \\
Education & $133(26.1)$ \\
Less than 9 years & $371(72.7)$ \\
At least 9 years & $6(1.2)$ \\
Missing replies & \\
HCV & $31(6.1)$ \\
Negative & $435(85.3)$ \\
Positive & $44(8.6)$ \\
Missing replies & \\
HIV & $429(84.1)$ \\
Negative & $61(12.0)$ \\
Positive & $20(3.9)$ \\
Missing replies &
\end{tabular}

SD: standard deviation; HCV: hepatitis C virus; HIV: human immunodeficiency virus.

heroin use was 11.96 years $(\mathrm{SD}=7.78)$. The average methadone dose was $51.62 \mathrm{mg} /$ day $(\mathrm{SD}=32.4)$ and mean duration of participating in the MMT was 183.86 days $(\mathrm{SD}=150.90)$. Most were males $(86.9 \%)$. The majority of the participants $(72.7 \%)$ had completed at least 9 years of compulsory schooling; $12 \%$ were HIV positive and over $85 \%$ were $\mathrm{HCV}$ positive.

\section{Score distributions}

As indicated in Table 2, the floor and ceiling effects in each domain score was low (0\%-1.0\%). For all WHOQOLBREF (TW) items, the percentage of lowest and highest scores was, in general, below $20 \%$. However, floor effects for the positive feelings facet $(20.0 \%)$ and for the financial resources facet $(21.2 \%)$ were observed. In addition, a ceiling effect for the dependence on medication or treatment facet $(24.5 \%)$ was notable.

\section{Reliability}

The estimated values of Cronbach's alpha for the physical health, psychological health, social relationships, and environment domains were $0.79,0.78,0.76$, and 0.87 (Table 2), respectively, confirming adequate internal consistency of the instrument. On corrected item-domain correlation, all 
Table 2 Internal consistency and score distribution of the WHOQOL-BREF (TW) in IDU $(n=510)$

\begin{tabular}{|c|c|c|c|}
\hline Domain and facet & $a$ & $\begin{array}{l}\text { Floor } \\
\text { effect (\%) }\end{array}$ & $\begin{array}{l}\text { Ceiling } \\
\text { effect (\%) }\end{array}$ \\
\hline Overall quality of life & & 2.7 & 3.3 \\
\hline General health & & 4.1 & 2.0 \\
\hline Physical health domain & 0.79 & 0.0 & 0.2 \\
\hline Pain and discomfort & & 2.7 & 13.5 \\
\hline $\begin{array}{l}\text { Dependence on medication } \\
\text { or treatment }\end{array}$ & & 2.9 & 24.5 \\
\hline Energy and fatigue & & 4.9 & 4.7 \\
\hline Mobility & & 4.3 & 9.4 \\
\hline Sleep and rest & & 7.5 & 3.5 \\
\hline Activities of daily living & & 1.8 & 3.5 \\
\hline Working capacity & & 3.1 & 5.1 \\
\hline Psychological health domain & 0.78 & 0.0 & 0.0 \\
\hline Positive feelings & & 20.0 & 1.2 \\
\hline Spirituality, religion and personal beliefs & & 12.9 & 6.5 \\
\hline $\begin{array}{l}\text { Thinking, learning, memory } \\
\text { and concentration }\end{array}$ & & 6.7 & 4.3 \\
\hline Body image and appearance & & 3.7 & 12.5 \\
\hline Self-satisfaction & & 4.3 & 6.9 \\
\hline Negative feelings & & 6.5 & 3.9 \\
\hline Social relationships domain & 0.76 & 0.8 & 1.0 \\
\hline Personal relationships & & 1.8 & 4.7 \\
\hline Sexual activity & & 5.9 & 4.1 \\
\hline Friend's support & & 2.2 & 4.1 \\
\hline Respect $^{\mathrm{a}}$ & & 6.3 & 2.7 \\
\hline Environment domain & 0.87 & 0.0 & 0.2 \\
\hline Physical safety and security & & 9.0 & 2.9 \\
\hline Physical environments & & 8.0 & 4.3 \\
\hline Financial resources & & 21.2 & 3.5 \\
\hline $\begin{array}{l}\text { Opportunities for new } \\
\text { information and skills }\end{array}$ & & 5.7 & 3.5 \\
\hline $\begin{array}{l}\text { Participation and support } \\
\text { of leisure activities }\end{array}$ & & 6.1 & 3.3 \\
\hline Home environment & & 1.6 & 7.5 \\
\hline $\begin{array}{l}\text { Heath and social care: } \\
\text { availability and quality }\end{array}$ & & 1.4 & 5.1 \\
\hline Transportation & & 2.0 & 4.5 \\
\hline Eating $^{a}$ & & 1.0 & 14.3 \\
\hline
\end{tabular}

WHOQOL-BREF (TW): the short Taiwan version of the World Health Organization Quality of Life assessment; IDU: injection drug user; ${ }^{\mathrm{a}}$ Taiwanese national items.

items had acceptable correlation coefficients (0.32-0.73) (data not shown in tables).

\section{Validity}

The Pearson's $r$ correlation coefficients of the 4 WHOQOLBREF (TW) domains and the criterion measures are shown in Table 3. All domain scores were fairly to moderately correlated with overall QOL $(0.40 \leq r \leq 0.52, p<0.01)$ and general health $(0.41 \leq r \leq 0.57, p<0.01)$. At the item level, all had fair to good relationships with the aforementioned indicators $(0.20 \leq r \leq 0.50, p<0.01)$ (data not shown in tables) except for the pain and discomfort facet with overall QOL $(r=0.11)$ (data not shown in tables) and for the dependence on medication or treatment facet with overall QOL $(r=0.12)$ (data not shown in tables).

A summary of the selected goodness-of fit indices for confirmatory factor analysis is presented in Table 4. The results of the original model with $\mathrm{CFI}=0.87, \mathrm{NNFI}=0.86$, and RMSEA $=0.073$, indicated that the existing domain structure with particular items did not adequately fit the IDUs. The model reached a good fit $(\mathrm{CFI}=0.92, \mathrm{NNFI}=$ 0.91 , RMSEA $=0.06$ ) when the physical safety and security facet (environment domain) was allowed to cross-load on the psychological health domain and when 5 pairs of error variances were allowed to covary (i.e., "pain and discomfort" and "dependence on medication or treatment"; "positive feelings" and "spirituality, religion and personal beliefs"; "physical safety and security" and "physical environments"; "energy and fatigue" and "physical environments"; "thinking, learning, memory and concentration" and "physical safety and security"). In the final proposed model, the four first-order factors were found to load highly and significantly on their secondorder factors (standardized loadings for physical health, psychological health, social relationships, and environment domains were $0.93,0.98,0.92$, and $0.88, p<0.05$, respectively) (data not shown in tables), suggesting adequate construct validity.

\section{Discussion}

The purpose of the current study is to examine the applicability of the WHOQOL-BREF (TW) in a group of IDUs enrolled in a MMT program. This is among the first reports of psychometric properties of the WHOQOL-BREF (TW) in this population group. Our findings suggest that the WHOQOL-BREF (TW) had acceptable reliability (internal consistency, and corrected item-domain correlation) and reasonable criterion-related validity, except for

Table 3 Criterion-related validity of the WHOQOL-BREF (TW) in IDU $(n=510)$

\begin{tabular}{lll}
\hline Domain & \multicolumn{2}{c}{ Criterion measure } \\
\cline { 2 - 3 } & Overall quality of life & General health \\
\hline Physical health domain & 0.44 & 0.57 \\
Psychological health domain & 0.51 & 0.56 \\
Social relationships domain & 0.40 & 0.41 \\
Environment domain & 0.52 & 0.49
\end{tabular}

WHOQOL-BREF (TW): the short Taiwan version of the World Health Organization Quality of Life assessment; IDU: injection drug user. All correlations were significant at the 0.01 levels. 
Table 4 Goodness-of-fit indices from confirmatory factor analysis

\begin{tabular}{|c|c|c|c|c|c|}
\hline & Best suggestion & $x^{2}$ & RMSEA $(90 \% \mathrm{Cl})$ & CFI & NNFI \\
\hline Original model & & 1093.71 & $0.073(0.068 \sim 0.078)$ & 0.87 & 0.86 \\
\hline Modified model 1 & add cov (Psyc7, En8) & 1025.10 & $0.070(0.065 \sim 0.075)$ & 0.89 & 0.87 \\
\hline Modified model 2 & add cov (En9, Phy10) & 965.93 & $0.067(0.062 \sim 0.072)$ & 0.89 & 0.88 \\
\hline Modified model 3 & add cov (Phy3, Phy4) & 906.85 & $0.064(0.060 \sim 0.069)$ & 0.90 & 0.89 \\
\hline Modified model 4 & add cov (Psyc5, Psyc6) & 856.15 & $0.062(0.057 \sim 0.067)$ & 0.91 & 0.90 \\
\hline Modified model 5 & add Psyc-En8 & 834.17 & $0.061(0.056 \sim 0.066)$ & 0.91 & 0.90 \\
\hline Final model & add $\operatorname{cov}($ En8, En9) & 812.49 & $0.060(0.055 \sim 0.065)$ & 0.92 & 0.91 \\
\hline
\end{tabular}

RMSEA: root mean square error of approximation; Cl: confidence interval; CFI: comparative fit index; NNFI: non-normed fit index.

Confirmatory factor analyses were performed while controlling for age, education, gender, HIV, HCV, duration of heroin use, methadone dose and days stayed in MMT at study interview.

the item related to pain and discomfort and the item assessing dependence on medication or treatment. Although the original domain structure of the WHOQOLBREF (TW) did not fit the data very well, there was a good fit after a few adjustments. Generally, the results support the reliability and validity of the WHOQOL-BREF (TW) for the IDU population and provide further information in regard to the IDU's QOL.

There were no floor or ceiling effects for the 4 domains. However, the positive feelings and financial resources facets showed significant floor effects. Because hopelessness is one of the neuropsychiatric consequences of $\mathrm{HCV} / \mathrm{HIV}$ infection or coinfection in drug users [34] and it has been found that most drug users have considerable financial strain [35-37], high values of the floor effect in the two items (i.e., "Do you enjoy your life? and "Do you have enough money for whatever you need?) were not unexpected. Similar to the finding in an earlier study, we found a notable ceiling effect in the dependence on the medication or treatment facet [24]. The high level of ceiling effect in the item (i.e., "Do you need medical treatment to cope with your daily life?") was not too surprising given that the majority of our study population comprised a relatively larger number of middleaged participants rather than the elderly.

Cronbach's alpha coefficients for the 4 domains of the WHOQOL-BREF (TW) were greater than the recommended standard of 0.70 , indicating satisfactory internal consistency of the instrument. This is consistent with a prior study conducted in Iran on 115 drug addicts, in which the alpha coefficients for 6 domains of WHOQoL100 ranged from .78 to .84 [38]. All the items of the WHOQOL-BREF (TW) had item domain correlations of 0.3 or greater in our study, which were above the minimum value of 0.2 [39], suggesting that the item had reasonable convergence with the domain in which it is included. The reliability of the WHOQOL-BREF (TW) was confirmed, with the values comparable to prior results [24,25].

The validity of an instrument concerns whether a test measures what it is intended to [40]. In the evaluation of the criterion-related validity, the 4 domain scores of the WHOQOL-BREF (TW) showed statistically significant correlations with the chosen criteria (i.e., overall QOL and general health). The good associations between the physical health, psychological health, social relationships, environment domains, and the criterion measures confirm agreement but not redundancy of these QOL-specific domains. At the item level, however, 2 items (i.e., "To what extent do you feel that your pain prevents you in doing what you need to do?" and "How much do you need any medical treatment to cope with your daily life?") showed weak criterion-related validity with overall QOL. Similar finding was also reported in a validation study of the Taiwanese audio player-assisted interview version of WHOQOL-BREF [41]. Because overall QOL involves a wide range of factors, it is possible that an individual item, which reflects only a narrow QOL facet, showed lower association with the criterion. In addition, chronic pain is prevalent among methadone patients [42] and is significantly associated with methadone daily dosage [43]. The weak relation between pain and discomfort with general health and overall QoL may reflect the low daily dose of methadone of our participants. Taken together, these findings lent support to the criterion-related validity of the WHOQOL-BREF (TW) for assessing QOL and general health in IDUs.

In regard to the construct validity of the WHOQOLBREF (TW), our factor-analytic results indicated a marginal acceptable model fit [44], which are in line with the findings from several WHOQOL-BREF psychometric studies. For instance, in 908 Polish healthy and sick respondents aged 18-85, a CFI of 0.87 was reported by Jaracz et al. [45]. Skevington et al. [46] found identical CFI values of 0.863 and 0.864 in two random samples of over 5000 adults (mean age $=40$ ) living in 23 countries. In exploring the factor structure of the Taiwanese version of the WHOQOL-BREF, Yao et al. [47] showed that the original factor structure needed revision $(\mathrm{CFI}=0.886)$. In order to achieve a better model fit, it is necessary to add error correlations [48]. Through covarying the error variances for items from different domains and allowing two 
items to cross-load on other domains, Hwang et al. [25] showed an increase on the Bentler's CFI from 0.85 to 0.90 . A Dutch study of women with breast cancer [49] found that the revised model, with the additional covariances between error terms, better represented the sample data in comparison to the initial model.

To modify the fit indices of the original model, we added a cross-loading (physical safety and security on psychological) and 5 inter-correlations: "pain and discomfort" with "dependence on medication or treatment", "positive feelings" with "spirituality, religion and personal beliefs", "physical safety and security" with "physical environments", "energy and fatigue" with "physical environments", and "thinking, learning, memory and concentration" with "physical safety and security". Although the association of the safety facet with the psychological health domain may suggest a deviation from the theoretical measurement structure, it informs us about the conceptualization of this item by the drug users. The correlated residuals with respect to two pairs of items suggest something in common to these items. However, the need to correlate errors to obtain a better-fitting model raises a question as to why items that overlap in content are necessary in the scale.

In addition to the 2 benchmark items, the short form of the WHOQOL-100 contains 24 items and each represents one facet of the original form. That is, the WHOQOLBREF includes 24 different QOL dimensions and the factor structure of the WHOQOL-BREF is formed depending on the correlations among the 24 QOL facets. However, it is unlikely that the correlations between the 24 QOL dimensions are the same across studies because there are differences in the demographic or clinical characteristics of the participant groups. For example, if one considers a subgroup of younger people and a subgroup of patients with HIV infection, it is very likely the item "sexual activity" will be differently related to other 23 items. Although the associations between the 24 QOL dimensions might differ between participant groups due to various reasons, it does not undermine the validity of the scale, but further shows how the QOL facets may link together in a different way. With a substantial sample size for the confirmatory factor analysis [50], this study demonstrates that the WHOQOL-BREF (TW) is a suitable scale for IDUs even though a few modifications are needed.

The results of the current study need to be considered in light of some limitations. First, because the vast majority of participants were male drug users, it is not possible to analyze whether gender has an effect on the measurement of QOL in IDUs. The second limitation concerns the generalizability of the findings. The study participants were recruited from methadone outpatient clinics in one geographic area and this group of injection drug users who share not only similar drug use behaviors but also exposure to the same modality of treatment. Thus, the results may not be generalized to other samples recruited from a different region. Third, our reliability evaluation of the instrument was limited to the tests of internal consistency. Lastly, due to the lack of specific psychological and functional-related information about the participants, it is not clear if such factors could have impacted the results. With these considerations in mind, this study provides good support for using the WHOQOL-BREF (TW) in QOL assessment among drug users. More research needs to be carried out to further examine the remaining psychometric properties of the instrument, such as the test-retest reliability and sensitivity to changes due to MMT over time.

\section{Conclusions}

This is among the first studies to evaluate psychometric characteristics of the WHOQOL-BREF (TW) in a population of drug users. Although a few items had floor and ceiling effects and there were slightly different patterns found in the confirmatory factor analysis, it appears that the WHOQOL-BREF (TW) is a reliable and valid instrument to measure QOL in IDUs. The factor structure provided by the study also helps us to understand the QOL characteristics of the drug users in Taiwan.

\section{Additional file}

Additional file 1: An English translation of WHOQOL-BREF [Taiwan].

\section{Abbreviations}

CFI: Comparative fit index; HCV: Hepatitis C virus; HIV: Human immunodeficiency virus; IDUs: Injection drug users; MMT: Methadone maintenance treatment; NNFI: Non-normed fit index; QOL: Quality of life; RMSEA: Root mean square error of approximation; SD: Standard deviation; TW: Taiwan; WHOQOL-BREF: The short version of the World Health Organization quality of life assessment.

\section{Competing interests}

The authors declare that they have no competing interests.

\section{Authors' contributions}

TSTF carried out the literature searches of previous related work, undertook the statistical analysis, interpreted the findings, and wrote the manuscript. TYC, WHW, HCW, and MYY participated in the study design, data collection and analysis. WTC and CRL contribute to the conceptual framework and interpretation of the results. TSHL conceived the study, designed the research, draft and revised the manuscript. All authors read and approved the final manuscript.

\section{Acknowledgements}

This research was supported by the National Bureau of Controlled Drugs Department of Health, Taiwan (Grant number DOH97-NNB-1044). This article was partially funded by National Science Council (NSC100-2628-H-003-002-MY3) through a post-doc fellowship to the first author. We are grateful for the assistance of the administrative staff and physicians of the participating hospitals and the local public health bureaus. We would also like to express our gratitude to all the respondents for their participation.

\section{Author details}

${ }^{1}$ Department of Health Promotion and Health Education, National Taiwan Normal University, No. 162, He-ping East Road, Section 1, Taipei 10610, Taiwan. ${ }^{2}$ Department of Psychiatry, New Taipei City Hospital, No.198, Yingshi 
Rd., Banqiao Dist., New Taipei City 220, Taiwan. ${ }^{3}$ Department of Infection, Taipei City Hospital, Branch for Disease Control and Prevention, No 100 Kunming Street, Taipei 10844, Taiwan. ${ }^{4}$ Department of Psychiatry, Ministry of Health and Welfare, Keelung Hospital, No 268 Sin 2nd Rd, Keelung City 20148, Taiwan. ${ }^{5}$ Department of Psychiatry, Lotung Poh-Ai Hospital, 83 Nan Chang St., Lotung, Yilan 265, Taiwan. ${ }^{6}$ School of Nursing, Yale University, New Haven, CT 06519, USA. ${ }^{7}$ Department of Psychiatry, Yale University School of Medicine, 34 Park Street, New Haven 06519, USA.

Received: 13 December 2011 Accepted: 2 December 2013

Published: 10 December 2013

\section{References}

1. Beyrer C, Wirtz AL, Baral S, Peryskina A, Sifakis F: Epidemiologic links between drug use and HIV epidemics: an international perspective. J Acquir Immune Defic Syndr 2010, 55(Suppl 1):S10-S16.

2. Taiwan Center for Disease Control: reported Cases of HIVIAIDS by exposure categon in Taiwan (1984-2009). [http://www.cdc.gov.tw/public/Data/0161631271.doc]

3. Trujols J, Sinol N, Iraurgi I, Batlle F, Guardia J, de los Cobos JP: Patient and clinician's ratings of improvement in methadone-maintained patients: differing perspectives? Harm Reduct J 2011, 8:23.

4. Ruefli T, Rogers SJ: How do drug users define their progress in harm reduction programs? Qualitative research to develop user-generated outcomes. Harm Reduct J 2004, 1:8.

5. Chen CY, Lin KM: Health consequences of illegal drug use. Curr Opin Psychiatry 2009, 22:287-292.

6. Gruber SA, Tzilos GK, Silveri MM, Pollack M, Renshaw PF, Kaufman MJ, Yurgelun-Todd DA: Methadone maintenance improves cognitive performance after two months of treatment. Exp Clin Psychopharmacol 2006, 14:157-164.

7. Faulkner BMR, Vollick DN, Judson M: Success in a Canadian methadone maintenance treatment program. Addict Disord Their Treat 2010, 9:75-86.

8. Trujols J, Pérez De Los Cobos J: La perspectiva de los usuarios sobre los tratamientos de mantenimiento con metadona. Una revision centrada en la satisfacción con el tratamiento [Users' views of methadone maintenance treatment: A review focused on satisfaction with treatment]. Adicciones 2005, 17(Suppl 2):181-204.

9. Padaiga $\breve{Z}$, Subata E, Vanagas G: Outpatient methadone maintenance treatment program. Quality of life and health of opioid-dependent persons in Lithuania. Medicina (Kaunas) 2007, 43:235-241.

10. Vanagas G, Padaiga Ž, Subata E: Drug addiction maintenance treatment and quality of life measurements. Medicina (Kaunas) 2004, 40:833-841.

11. Puigdollers E, Cots F, Brugal MT, Torralba L, Domingo-Salvany A: Programas de mantenimiento de metadona con servicios auxiliares: un studio de coste-efectividad [Methadone maintenance programs with supplementary services: a cost-effectiveness study]. Gac Sanit 2003, 17:123-130

12. Torrens M, San L, Martinez A, Castillo C, Domingo-Salvany A, Alonso J: Use of the Nottingham health profile for measuring health status of patients in methadone maintenance treatment. Addiction 1997, 92:707-716.

13. Reynolds GL, Fisher DG, Klahn JA, Wood MM: Using the quality of well-being scale to assess quality of life in out-of-treatment drug users. J Psychoactive Drugs 2003, 35:497-502.

14. Costenbader EC, Zule WA, Coomes CM: The impact of illicit drug use and harmful drinking on quality of life among injection drug users at high risk for hepatitis C infection. Drug Alcohol Depend 2007, 89:251-258.

15. Deering DE, Frampton CMA, Horn J, Sellman JD, Adamson SJ, Potiki TL: Health status of clients receiving methadone maintenance treatment using the SF-36 health survey questionnaire. Drug Alcohol Rev 2004, 23:273-280.

16. Ducray K, Byrne P, Burke C, Smyth BP: A comparison of the drug use patterns, measures of needs and quality of life of methadonemaintained patients using and not using cocaine. Heroin Addict Relat Clin Prob/ 2011, 13:27-38

17. Lin C, Wu Z, Detels R: Family support, quality of life and concurrent substance use among methadone maintenance therapy clients in China. Public Health 2011, 125:269-274.

18. Group WHOQOL: Development of the WHOQOL: rationale and current status. Int J Mental Health 1994, 23:24-56.

19. Group WHOQOL: The World Health Organization Quality of Life assessment (WHOQOL): position paper from the World Health Organization. Soc Sci Med 1995, 41:1403-1409.
20. Group WHOQOL: The World Health Organization Quality of Life assessment (WHOQOL): development and general psychometric properties. Soc Sci Med 1998, 46:1569-1585.

21. Group WHOQOL: Development of the World Health Organization WHOQOL-BREF quality of life assessment. Psychol Med 1998, 28:551-558.

22. The WHOQOL-Taiwan Group: User manual of the WHOQOL-BREF Taiwan version Taipei, Taiwan: National Taiwan University College of Public Health Press; 2000.

23. Yao G, Wang JD, Chung CW: Cultural adaptation of the WHOQOL questionnaire for Taiwan. J Formos Med Assoc 2007, 106:592-597.

24. Chen $\mathrm{KH}, \mathrm{Wu} \mathrm{CH}$, Yao G: Applicability of the WHOQOL-BREF on early adolescence. Soc Indic Res 2006, 79:215-234.

25. Hwang HF, Liang WM, Chiu YN, Lin MR: Suitability of the WHOQOL-BREF for community-dwelling older people in Taiwan. Age Ageing 2003, 32:593-600.

26. Liang WM, Kuo HW, Lin CF, Shy HY, Chen HW, Chen JJ: Factor construct of health-related quality of life in Taiwanese workers by WHOQOL-BREF questionnaire. Mid Taiwan J Med 2005, 10:113-122.

27. Jang $Y$, Hsieh $\mathrm{CL}$, Wang $\mathrm{YH}, \mathrm{Wu} \mathrm{YH}$ : A validity study of the WHOQOL-BREF assessment in persons with traumatic spinal cord injury. Arch Phys Med Rehabil 2004, 85:1890-1895.

28. Yang SC, Kuo PW, Wang JD, Lin MI, Su S: Development and psychometric properties of the dialysis module of the WHOQOL-BREF Taiwan version. J Formos Med Assoc 2006, 105:299-309.

29. Higginson IJ, Carr AJ: Measuring quality of life: using quality of life measures in the clinical setting. BMJ 2001, 322:1297-1300.

30. Holmes W, Shea J: Performance of a new, HIV/AIDS-targeted quality of life (HAT-QoL) instrument in asymptomatic seropositive individuals. Qual Life Res 1997, 6:561-571.

31. Nunnally JC, Bernstein IR: Psychometric theory. New York: McGraw-Hill; 1994

32. Bentler PM: EQS Structural equations program manual. Rncino, CA: Multivariate Software; 1995

33. Browne N, Cudeck R: Single sample cross-validation indices for covariance structures. Multivariate Behav Res 1989, 24:445-455

34. Khalsa $\mathrm{JH}$, Elkashef $\mathrm{A}$ : Interventions for HIV and hepatitis $\mathrm{C}$ virus infections in recreational drug users. Clin Infect Dis 2010, 50:1505-1511.

35. Catto $\mathrm{M}$, Thomson N: Review of illicit drug use among Indigenous peoples. Aust Indigenous Health Bull 2008, 8:1.

36. Clough A, d'Abbs P, Cairney S, Gray D, Maruff P, Parker R, O'Reilly B: Emerging patterns of cannabis and other substance use in aboriginal communities in Arnhem land, northern territory: a study of two communities. Drug Alcohol Rev 2004, 23:381-390.

37. Holly C, Shoobridge J: Investigating the impact of injecting drug use in indigenous communities in metropolitan Adelaide. Adelaide: Aboriginal Drug and Alcohol Council; 2002

38. Akbari B, Andalib M, Andalib S, Khakbiz K, Safarpour H: Reliability and factor analysis of WHOQoL-100 questionnaire for drug addicts in Guilan, Iran. J Basic App/ Sci Res 2012, 2:8627-8631

39. Streiner DL, Norman GL: Health Measurement Scale: a practical guide to their development and use. Oxford: Oxford University Press; 1995.

40. Portney LG, Watkins MP: Foundations of Clinical Research: applications to practice. Pearson/Prentice Hall: Upper Saddle River, NJ; 2009.

41. Chien CW, Wang JD, Yao G, Sheu CF, Hsieh CL: Development and validation of a WHOQOL-BREF Taiwanese audio player-assisted interview version for the elderly who use a spoken dialect. Qual Life Res 2007, 16:1375-1381.

42. Rosenblum A, Joseph H, Fong C, Kipnis S, Cleland C, Portenoy R: Prevalence and characteristics of chronic pain among chemically dependent patients in methadone maintenance and residential treatment facilities. JAMA 2003, 289:2370-2378.

43. Peles E, Schreiber S, Gordon J, Adelson M: Significantly higher methadone dose for methadone maintenance treatment (MMT) patients with chronic pain. Pain 2005, 113:340-346. doi:10.1016/j.pain.2004.11.011.

44. Bentler P: Comparative fir indexes in structural models. Psychol Bull 1990 107:238-246.

45. Jaracz K, Kalfoss MH, Gorna K, Baczyna G: Quality of life in Polish respondents: psychometric properties of the Polish WHOQOL-Bref. Scand J Caring Sci 2006, 20:251-260.

46. Skevington SM, Lotfy M, O'Connell KA: The World Health Organization's WHOQOL-BREF quality of life assessment: psychometric properties and results of the international field trial. A report from WHOQOL group. Qual Life Res 2004, 13:299-310. 
47. Yao G, Chung CW, Yu CF, Wang JD: Development and verification of the validity and reliability of the WHOQOL-Bref Taiwan version. $J$ Formos Med Assoc 2002, 101:342-351.

48. Mota CP, Matos PM, Lemos MS: Psychometric properties of the social skills questionnaire: Portuguese adaptation of the student form (Grades 7 to 12). Span J Psychol 2011, 14:486-499.

49. Van Esch L, Den Oudsten BL, De Vries J: The World Health Organizetion Quality of Life Instrument - short form (WHOQOL-BREF) in women with breast problems. Int I Clin Health Psychol 2011, 11:5-22.

50. Crowley SL, Fan X: Structural equation modeling: basic concepts and applications in personality assessment research. J Pers Assess 1997, 68:508-531.

doi:10.1186/1477-7517-10-37

Cite this article as: Fu et al: Psychometric properties of the World Health Organization quality of life assessment - brief in methadone patients: a validation study in northern Taiwan. Harm Reduction Journal 2013 10:37.

\section{Submit your next manuscript to BioMed Central and take full advantage of:}

- Convenient online submission

- Thorough peer review

- No space constraints or color figure charges

- Immediate publication on acceptance

- Inclusion in PubMed, CAS, Scopus and Google Scholar

- Research which is freely available for redistribution 